\title{
La noción socioambiental Del derecho a la Ciudad
}

The socio-environmental notion of the Right to the City

\section{Anibal Alejandro Rojas Hernández'}

1 Universidad Nacional de Colombia, Bogotá, Colombia. E-mail: anilejo@hotmail.com. ORCID: https://orcid.org/0000-0002-3379-1932.

\section{Paula Harumi Kanno 2}

2 Pontifícia Universidade Católica do Paraná, Curitiba, Paraná, Brasil. E-mail: paula_harumi@hotmail.com. ORCID: https://orcid.org/0000-0003-1391-1631.

\section{Carlos Frederico Marés de Souza Filho ${ }^{3}$}

3 Pontifícia Universidade Católica do Paraná, Curitiba, Paraná, Brasil. E-mail: carlosmares@terra.com.br. ORCID: https://orcid.org/0000-0001-6529-6058.

Artigo recebido em 04/02/2020 e aceito em 10/02/2020.

\section{$(\mathrm{cc}) \mathrm{EY}$}

This work is licensed under a Creative Commons Attribution 4.0 International License. 


\title{
Resumen
}

Espacio urbano y espacio rural son las dos caras de una misma moneda, no necesariamente por el servir como espacio de vida, sino, por ser espacios que se produjeron en torno al capital. Producción que facilitó a los ciudadanos vivir con sus privilegios y a las gentes, servir como mano de obra. El espacio produce y excluye en medio de una falla metabólica de la naturaleza que hace que lo socioambiental sea el lugar donde retornen los que la modernidad expulsó y con ellos, un dique de contención para la vida, para un derecho a la ciudad socioambiental.

Palabras clave: Socioambiental; Naturaleza; Derecho a la ciudad; Mercancía; Valor de uso.

\begin{abstract}
Urban space and rural space are the two sides of the same coin, not necessarily for serving as a living space, but for being spaces that were produced around capital. Production that made it easier for citizens to live with their privileges and for people, to serve as labor. The space produces and excludes in the midst of a metabolic failure of nature that makes the socio-environmental the place where the modernity expelled and with them, a containment dam for life, for a right to the socio-environmental city.

Keywords: Socio-environmental; Nature; Right to the city; Commodity; Use value.
\end{abstract}


Introducción

El siglo XXI es un tiempo de rarezas paradójicas. Es el siglo en el que los seres humanos logran producir espacios, incluso virtuales, apropiándoselos de tal forma que se tornen siempre exclusivos, usados por unos pocos en detrimento de otros tantos. No importa si el espacio es real o virtual, la compulsión por cercarlo, fragmentarlo y excluirlo de todo uso común es un deseo inevitable que le es inquebrantable. No importa si son finitos o infinitos, tienen que ser demarcados y categorizados para que entren al mercado. Un sólo espacio que no esté acotado y condicionado en el s. XXI se hace algo más que una excepción a la regla, es un desafío a la noción del ciudadano, al del Estado moderno que priorizó a las gentes en razón a su patrimonio. Es un desafío al espacio físico sobre el cual el hombre blanco creó subterfugios para justificarlo apropiado, importando poco la violencia ejercida y siempre argumentando lo trascendental que es para el capital y el modo de vida actual normalizar tal despojo. Quizás esa sea la explicación del distinguido y refinado aroma europeo a sangre y sudor que el s. XXI se esmera por preservar.

Los seres humanos que están en el espacio suelen ser secundarios, pues tanto la vida como la felicidad son mercancías que en el s. XXI son conmensurables e intercambiables. No hay nada que se escape a generar alguna equivalencia que le permita generar valores de cambio. Nada, incluida la ciudad, quienes viven en ella y los que sobreviven fuera de ella. Pareciera que aún resisten borrosos resquicios de un mundo lleno de valores de uso cuando dos personas se agradecen en la fila del supermercado o en las gentes que residen en la naturaleza retornando siempre a ella, por ella y gracias a ella.

Los espacios y quienes los habitan generan relaciones que necesariamente se interconectan o, que por lo menos intentan hacerlo. Morir en el mismo lugar en el que se creció se convirtió más en una digna historia de Gabriel García Márquez narrando las aventuras de José Arcadio Buendía, que del s. XXI y su modernidad. La ciudad y el campo, incluida la naturaleza y el techo en el que se vive dependen más de la lotería de la vida que del trabajo o de la historia que en el espacio habita.

Una hipótesis: la segunda década de los Estados Plurinacionales permitió entrever que el Estado sin importar su matiz, su apellido o sus principios plasmados de 
buenos propósitos, tiene una cierta autonomía relativa que lo empuja ineludiblemente a su lugar de origen: el capital. El Estado como abstracción sobrevivió el siglo pasado gracias a los ciudadanos-propietarios y hoy sobrevive por los ciudadanos globales "que viven mayormente sus vidas en una naturaleza prístina, ya sea haciendo trekkingen la Patagonia o nadando en las translúcidas aguas de sus islas privadas" (ZIZEK, 2009, p. 11). Que no dejan ser los mismos ciudadanos-propietarios que hicieron del Estado un instrumento que añora despolitizar la política, hacer de la sociedad un blanco de la felicidad a ser alcanzada y de la naturaleza el adversario a derrotar. Son los ciudadanos globales los que adoran las manifestaciones por el clima y repudian las acciones de la COP25 mientras se encierran en las burbujas culturales urbanas añorando tener un helipuerto que les calme la angustia del tráfico en São Paulo o Bogotá y consideran que todos tenemos que hacer un esfuerzo para generar desarrollo. Para los ciudadanos globales los proyectos hidroeléctricos como Itaipú o Hidroituango son esfuerzos colectivos que todos asumimos: ellos, pagando la tarifa mensual del servicio público, las gentes con su vida, su patrimonio cultural y su territorio.

Tal como lo mencionó Lefebvre: "Es el espacio y por el espacio donde se produce la reproducción de las relaciones de producción capitalista. El espacio deviene cada vez más un espacio instrumental." (2013, p. 223). Y es que el producir espacios es un elemento esencial para la reproducción del capital y las relaciones que en él se transforman y dinamizan. Excluir lo socioambiental de la ciudad no es solo evitar y garantizar toda posible oposición, además normaliza los lazos híbridos en torno a las relaciones que se desdoblan dentro del espacio urbano y perpetua el contrato ciudadano (Lefebvre, 1991). Lazos mediados por la moderna responsabilidad individual del capitalismo verde que culpa a los sujetos y no a los modos de producción y, por otro lado, consolida las estructuras simbólicas y culturales que solidifican las victorias por el cómo y quién construye el significado de lo urbano, la naturaleza y las personas que fluctúan e interactúan en ellas.

En la práctica, lo socioambiental es un elemento esencial para reivindicar un derecho a la ciudad. Cuestionar el contrato de la ciudadanía es cuestionar el contrato social que posibilitó un cierto sentido común y que, desde lo socioambiental, disputa la hoy evidente desconexión de la democracia y el capitalismo. Un derecho a la ciudad que sea colectivo precisa reñirse con la producción del espacio urbano desde una concepción 
amplia de la naturaleza como la que ofrece Carlos Frederico Marés de Souza Filho (2017) en donde lo socioambiental se presenta como una potentia (Spinoza, 1990) que disputalos significantes al conceder una legitimidad de acción a las reivindicaciones populares, advirtiendo la correlación de las gentes con el espacio que habitan.

En el prólogo de la Contribución a la crítica de la economía política Marx recuerda que "El modo de producción de la vida material determina el proceso social, político e intelectual de la vida en general. No es la conciencia de los hombres lo que determina su ser, es su existencia social lo que determina su conciencia. $(2008$, p. 3). Habrá que revisar si al segundo centenario de tal aforismola jerarquía de los grupos sociales aún existe o, si el capital en su fase actual ha logrado suprimir dentro de su imaginario ideológico las contradicciones necesarias de una democracia republicana que agoniza en sus propios ideales: ciudadanos libres y felices dispuestos a comprar siempre y cuando no haya fila en el supermercado.

\section{De gentes a ciudadanos y la fila del supermercado}

No hay duda de que la modernidad es un largo y complejo proceso que devino como resultado de profundas transformaciones no solamente en el ámbito de lo político o económico, también en lo cultural y lo filosófico. El papel del sujeto a partir de Descartes, junto con la victoria de la sociedad patriarcal (FEDERICI, 2010) son dos puntos de partida que se hacen vitales para preguntarse:¿cómo la modernidad produjo espacios y generó las reglas mediante las cuales los seres humanos se relacionarían en él?

Quizás sea más sencillo partir desde dos de los elementos que se hacen transversales a todo el proceso del que emergió la modernidad: el capital y la violencia que él ejerce a todas las formas sociales que lo precedieron o cuestionaron. Y es que el movimiento que constituyó al capital es similar al de la naturaleza. El capital sobrevive bajo un dinamismo que hace que se mantenga a flote gracias a modelos nuevos o técnicas inéditas que le permiten adquirir experiencia y, un cierto grado de resistencia para salir airoso de todas las crisis que lo anteceden y rehacen constantemente. Algo 
similar a la resiliencia de la naturaleza y las gentes que la habitan, vidas que no desisten de retornar al espacio del que la modernidad excluyó.

Tanto la revolución francesa como la independencia de los Estados Unidos marcaron acontecimientos políticos que reorganizaron la realidad y promovieron las condiciones de posibilidad para dar el salto que Marx usó intuir las leyes bajo la cual, según él, ondulaba la historia: las luchas de clases. Conflictos sociales a los que Marx les guardó cierta fascinación tanto por su complejidad como por su potencia transformadora, pues ambas revoluciones burguesas coincidieron con la contrafigura de la violencia: el poder. De ahí una de las conclusiones de Arendt:

La violencia, es preciso recordarlo, no depende del número o de las opiniones, sino de los instrumentos, y los instrumentos de la violencia, al igual que todas las herramientas, aumentan y multiplican la potencia humana (...). El dominio por la pura violencia entra en juego allí donde se está perdiendo el poder. (2006, p. 73)

La realidad que se constituyó en el siglo XIX no solamente le daba la centralidad a las luchas de clases, también posicionaba a la partera de la historia marxiana como el clivaje político que establecería el escenario bajo el cual se delimitaría el devenir de la Europa pre-moderna a la moderna. Una modernidad que nunca abandonó la violencia, solo aprendió a encubrirla para salvaguardar los intereses de la clase dominante bajo una apariencia fantasmagórica, "la modernidad no se define, precisamente, por su aversión a esta. La violencia es proteica." (HAN, 2016, p. 9). Ahí es donde descansa la paradoja que convirtió a las gentes en ciudadanos, pues todo ciudadano de la modernidad es libre contractualmente siempre y cuando no sea un obstáculo para la propiedad privada de la tierra y el consumo que de ella se extrae.

Los procesos de institucionalización y gestión de la violencia fue lo que posicionó a la modernidad capitalista siempre con la intención de pacificar las luchas de clases $y$, al mismo tiempo, contener las contradicciones de clase que se generan en su interior. El sistema jurídico y la lucha del positivismo normativista kelseniano por ser hegemónico, no es más que la misma tendencia devoradora del capitalismo en su fase imperialista pero llevada al campo jurídico demandando universalidad. La dificultad de cuestionar la ficción jurídica moderna está en la forma contractual que adoptó el positivismo pues este, a partir de Kelsen, supuso que la Constitución Política es válida 
por antonomasia y todo aquello que esté fuera de ella no solo controvierte una ficción legal, cuestiona el sistema en su totalidad.

La justicia es, en primer lugar, una característica posible mas no necesaria del orden social. Recién en segundo término constituye una virtud del individuo pues un hombre es justo cuando su obrar concuerda con el orden considerado justo. Mas, ¿cuándo es justo un orden social determinado? Lo es cuando regla la conducta de los hombres de modo tal que da satisfacción a todos $y$ a todos les permite lograr la felicidad. (KELSEN, s. f., $p, 1$ )

Desactivar cualquier discusión del pacto político que constituyó la noción moderna del Estado -lo que bautizó Kelsen como la norma hipotética fundamental- es lo que permite que, en los intersticios, la violencia se ejerza al impedir cuestionar las ficciones jurídicas que edificó el capital para afianzarla base del sistema representado en la propiedad privada y el trabajo libre: el Código Civil y la Constitución Política. El Código Civil generando propietarios capaces de contraer obligaciones jurídicas, la Constitución, garantizando que tales propietarios contarán con seguridad jurídica para realizar sus negocios jurídicos. De ahí pareciera surgir una de las claves del Estado neoliberal, una forma estatal que los conflictos sociales parecieran no afectarle su núcleo ni al núcleo del capital.

Por su parte, la teoría marxiana del Estado se ha condensado en la celebre frase del Manifiesto del Partido Comunista: "El gobierno del Estado moderno no es más que una junta que administra los negocios comunes de toda la clase burguesa" (MARX; ENGELS, 2011, p. 33) que Marx y Engels complejizaron al identificarla existencia de una autonomía relativa (ELSTER, 1985) y que en el 18 Brumario de Luis Bonaparte entienden que:

(...) para mantener intacto su poder social tiene que quebrantar su poder político; que los individuos burgueses sólo pueden seguir explotando a otras clases y disfrutando apaciblemente de la propiedad, la familia, la religión y el orden bajo la condición de que su clase sea condenada con las otras clases a la misma nulidad política; que, para salvar la bolsa, hay que renunciar a la corona, y que la espada que había de protegerla tiene que pender al mismo tiempo sobre su propia cabeza como la espada de Damocles" (MARX; ENGELS, 1981, p. 52).

Definición que se presta para mostrar que la clase burguesa además de ceder el poder estatal para evitar una confrontación directa con la clase obrera, generó una alternativa política que coordina sus intereses y salvaguarda la apariencia democrática del Estado mientras, simultáneamente, apacigua las contradicciones que se organizan en 
torno a sus prácticas de clase. Tal como sucede en Colombia, donde la herencia colonial custodia una burguesía agraria que se mantiene en una constante oposición a la burguesía urbana pero que, a la hora de juntar y consolidar sus intereses de cara a una lucha electoral, hacen un bloque común que pacta el alcance de las políticas gubernamentales y los interregnos en los que continúan irremediablemente sus contradicciones.

Eso permite comprenderlo fangoso que puede llegar a ser el dimensionar la magnitud y capacidad de los movimientos que se constituían en el cruce de relaciones de la superestructura y el modo de producción imperante, frente alas otras múltiples articulaciones posibles que se dan en su matriz. Bien lo explica Poulantzas al definir desde una heterodoxia marxiana el alcance y significado de un modo de producción; excluyéndolo de una simple mirada economicista y acercándolo a fenómenos históricos que se caracterizan por las particularidades ambientales, sociales y culturales de cada grupo social

Por modo de producción no se designará lo que se indica en general como económico, las relaciones de producción en sentido estricto, sino una combinación específica de diversas estructuras y prácticas que, en su combinación, aparecen como otras tantas instancias o niveles, en suma, como otras tantas estructuras regionales de aquel modo. Un modo de producción, como dice de una manera esquemática Engels, comprende diversos niveles o instancias: lo económico, lo político, lo ideológico y lo teórico, entendiéndose que se trata ahí de un esquema indicativo y que puede operarse una división más completa. El tipo de unidad que caracteriza un modo de producción es el de un todo complejo con predominio, en última instancia, de lo económico, predominio en última instancia para el que se reservará el nombre de determinación. (...) lo económico en realidad sólo es determinante en la medida en que asigna a tal o cual instancia el papel dominante, es decir, en la medida en que regula el desplazamiento de predominio debido a la descentralización de las instancias. Así, Marx nos indica cómo, en el modo de producción feudal, la ideología -en su forma religiosa- es la que detenta el papel predominante, lo que está rigurosamente determinado por el funcionamiento de lo económico en aquél modo. Lo que distingue pues, un modo de producción de otro, y que, por consiguiente, específica un modo de producción, es esa forma particular de articulación que mantienen sus niveles: es lo que en adelante se designará con la palabra matriz de un modo de producción. (POULANTZAS, 2001, p. 4-7)

El ejemplo clásico para ello es el que evocó Poulantzas (2001) intentando mostrar que, si bien el modo de producción del feudalismo era un elemento determinante para comprender grupos sociales feudales, era el elemento religioso el 
que lograba coordinar predominantemente la matriz de las sociedades feudales. Poulantzas reveló que sin la religión el feudalismo no se hubiera logrado coordinar como se coordinó y que, sin la particularidad histórica de las fabricas inglesas de lino en Leeds, quizás hubiera sido imposible que Marx y Engels diagnosticaran la semilla de la forma capitalista moderna. No sólo importa el elemento económico del capital, importan las gentes a las que sometió, la historia que arrasó y la forma en que promueve relaciones sociales ajenas a quienes antes allí estaban para ocultar una noción socioambiental de quienes habitaban el espacio, lo protegían y significaban.

Es ahí donde emerge la heterodoxia marxiana para mostrar que el Estado no es pura violencia física, por el contrario, el Estado es un cúmulo de poder y violencia que le permiten mantenerse hegemónico e incuestionable gracias a otras múltiples razones, por ejemplo, la producción de espacios sociales que moldean a las gentes en ciudadanos.

Por ello, es esencial el recuento que realiza Nancy Fraser para retomar la discusión sobre la reproducción ampliada del capital (2015), pues ayuda a rememorar que tanto la expansión del capitalismo en sus diferentes fases, como la subjetivación que generó -y continúa generando-, es un fenómeno ineluctable al momento histórico en el que convive todo aquél que esté sometido a la modernidad occidental. Eso da algunas luces del cómo el capitalismo mutó de lo visible a lo invisible; de lo real a lo virtual. Fragmentar a los seres humanos y usarla producción del espacio social que le es favorable se hace vital para atomizar identidades que en un pasado no muy lejano se encontraban en espacios urbanos o rurales forjando lazos sociales $y$, con ello, agrietar todo espacio común por ser altamente contaminante a los ideales occidentales, la prominencia por el valor del tiempo, la individualidad y la competencia.

Gentes capaces de gestionarse comunalmente no solo es un agravio al sistema económico, es una afrenta a la ética imperante de la ambición y la acumulación que abandona las formas contractuales que todo lo vende, todo lo compra, que todo lo mercantiliza. El capital y su fase neoliberal es más que un sistema económico, es un sentido común que teje los ideales sociales y, al mismo tiempo, lo que es reprochable. El tiempo, aquella noción moderna y valiosa que surge gracias a la necesidad de navegar el océano para explotar riquezas fuera de Europa, se hace tan precioso en la actualidad que hacer una fila en un supermercado se puede convertir en un espacio para generar 
una revolución, ya sea contra el supermercado o, como sucedió en las vísperas de la revolución francesa, cuando mujeres haciendo fila para poder comer un pedazo de pan se levantaron en contra de Luis XVI:

Las revueltas de la harina marcaron gran parte de las jornadas revolucionarias y movilizaron especialmente a las mujeres. Fue el consumo, no la producción, lo que produjo una movilización basada en la comunidad popular. (...) La muchedumbre marchó hacia Versalles para capturar a la familia real cantando: 'Cherchons le boulanger, la boulangère et le petitmitron'. (MANN, 1997, p. 273)

$Y$ es que la potentia de los seres humanos se fragua por lo general en los resquicios del pasado que le hacen recordar que la intensidad de las transformaciones sociales suele devenir de los lazos que se generan en comunidad. Lazos que se generan gracias a lo común: el aire, el agua, la tierra o en aquellas situaciones donde, por un segundo, el capital iguala a los seres humanos como ciudadanos ávidos por consumir y no desperdiciar el valioso y escaso tiempo: la fila del supermercado.

Cuatro son las características esenciales que Nancy Fraser (2015) rescata del trabajo de Marx para comprender al capital en su complejidad: a) la propiedad privada de los medios de producción; b) el mercado de trabajo libre; c) el valor autoexpasivo del capital y d) la producción de mercancías mediante otras mercancías. Características que complejizan el capital en su fase económica y que permite entenderlo con relación a todas instituciones sociales que emergen contingentemente gracias a él. Tal como sucede con la producción del espacio en el mundo urbano que pareciera haber abandonado la disputa por lo común.

La reproducción ampliada del capital, o mejor, la reproducción de todos los factores que generan las condiciones de posibilidad para la existencia del capital se manifiesta en la tensión que progresa entre la necesidad de expulsar la naturaleza de la producción del espacio urbano y, al mismo tiempo, mantener la viabilidad de las condiciones necesarias para la reproducción de la fuerza de trabajo. Aunque se presenta como una mera disputa es algo que va más allá, es la lucha por moldear el espacio en el que cohabitan tanto los seres humanos, como los elementos ideológicos que lo expropian para hacerlo privado. A lo que Lefebvre le prestó una especial atención en virtud de lo que significaba tener ciencias parcelarias que aparentaban -como toda ciencia- una neutralidad pero que, al ser examinadas más detenidamente, no deja de 
instrumentalizar el conocimiento a beneficio del capital. Lo que él denomina como la 'ideología urbanística'. (1978, p. 66; 67).

$\mathrm{Si}$ bien es cierto que el capital ha logrado solventar muchas de las contradicciones que le eran implícitas, la del espacio urbano y rural no ha logrado solventarlas. Cuestión que se hace todavía más evidente en ciudades como Bogotá, Ciudad de México, Lima, Rio de Janeiro o São Paulo que con el arsenal jurídico genera ciudadanos y ciudadanas para el consumo, pero no es capaz de garantizar el acceso al trabajo, los servicios públicos o si quiera, el flujo de los ciudadanos en donde se concentra la mayor parte de prestación de bienes y servicios. Es por ello por lo que "La ciudad y la realidad urbana son reveladoras del valor de uso". (LEFEBVRE, 1978, p. 20)

La expropiación como instrumento jurídico es quizás una de las ficciones jurídicas más interesantes de la modernidad pues se legitimó gracias al sistema jurídico e inmediatamente se clausuró exclusivamente a la expansión del capital. La expropiación se hace vital para generar desposesión y transformar el espacio mediante los instrumentos estatales mientras que, paralelamente, trasmutan las interacciones de las relaciones sociales de producción. Es desde ahí donde las administraciones locales, casi siempre en consonancia con el Estado, cumplen el papel instrumental que permite sustraer lo humano -el amor, los sueños, la alegría, etc.- a la condición intrínseca del consumo, empujando a los individuos a relacionarse casi de forma infranqueable por algún tipo de consumo.

La conciencia social, poco a poco, va cesando de tomar como punto de referencia la producción, para centrarse alrededor de la cotidianidad, del consumo. Con la implantación de suburbios se esboza un proceso, que descentra la Ciudad. El proletariado, separado de la Ciudad, terminará por perder el sentido de la obra. Apartado de los medios de producción, disponible a partir de un sector de hábitat para actividades esparcidas, dejará atrofiar en su conciencia la capacidad creadora. (LEFEBVRE, 1978, p.34)

Lefebvre muestra como esencial el doble proceso que vive Europa en el cual se genera tanto la industrialización como la urbanización en paralelo con la producción económica y la vida social. Conclusión lógica para la mayoría de los países europeos que habían alcanzado las revoluciones liberales del siglo XIX junto con una 'democratización' de la tierra pero que, en América Latina y en especial, en Colombia dista y por mucho. La revolución liberal, en términos de materialismo histórico perdió la batalla en la guerra 
de los mil días y, desde ese momento Colombia lo único que logró fue establecer en todo el s. XX fueron pactos intermediados por la institucionalidad de la clase social que tenía como su elemento central la propiedad de la tierra.

El tipo de ciudad que florece en Colombia y especialmente Bogotá, es una ciudad que sobrevive del colonialismo interno (MARIATEGUI, 2007) con débiles- o muchas veces nulos- procesos de industrialización que no produjo obreros u obreras sino, cientos de desposeídos que difícilmente alcanzan a generar un tejido urbano que impide, por tanto, que aparezcan otros fenómenos culturales, sociales y económicos. Las personas que se ven obligadas a habitar la ciudad llegan a ella por la desposesión que generalmente se ha dado por los conflictos armados internos que datan de comienzos del siglo XX en Colombia o, por la apropiación ilegal que ha sido consentida por el Estado a favor de los grandes hacendados.

Son entonces aquellas gentes desposeídas las que no alcanzan a ser ciudadanas y que se ven obligados a conviviren el espacio que el sistema los empuja, por regla general a una periferia sin acceso al agua, a la luz eléctrica o alcantarillado. Son las gentes las que sufren la ciudadanía en la medida en que el Estado les reprocha su conducta si fuese necesario, pero, al mismo tiempo, los expulsa al espacio que no pretende si quiera controlar y en el que los mercados informales de la propiedad del suelo gobiernan con aquiescencia de la burocracia estatal.

\begin{abstract}
Las condiciones específicas en el caso de Bogotá estarían determinadas aparentemente porque los procesos de ocupación informal del suelo se han dado en forma pausada y relativamente pacífica si se compara con otras ciudades, pues la invasión, el conflicto y el enfrentamiento con ciertos niveles de violencia no ha sido la pauta en Bogotá. Además, las ocupaciones se han dado en su mayoría sobre propiedades particulares, a diferencia de otros países de la región, donde se ocupan suelos de propiedad pública o estatal. En el caso bogotano se suelen ocupar terrenos públicos en zonas de restricción ambiental o hídrica que están bajo la tutela de entidades de servicios públicos, entonces, el crecimiento urbano informal ha estado condicionado a la existencia de suelo privado. En consecuencia, la figura de invasión es históricamente mínima respecto al loteamiento ilegal o, más coloquialmente, "urbanización pirata" (HURTADO; CAMARGO, 2013, p. 83)
\end{abstract}

Estas pues, son las gentes que no logran llegar ni a la fila del supermercado, pues el valor de uso de los lugares donde se desarrolla todas las actividades de la ciudad les está vedadas tanto por su valor económico, como por el carácter de clase que el 
neoliberalismo ha difuminado lentamente y que comienzan a naturalizar las prácticas de la clase dominante.

Abrazando al Leviatán: del miedo a la felicidad

El modelo capitalista rentista de compadrazgo en Colombia ha sido la fuente principal para la creación del Estado y la delimitación de sus fines y principios. El Estado es muchas cosas a la vez, unas inmateriales y otras no; unas dadas por las condiciones históricas de cada sociedad y otras, por las batallas que se han dado en su interior. Pēterislvánovich Stučka (1974) concibió al derecho como una relación social, es decir, como una institución que se modificaba conforme la sociedad iba avanzando a lo largo de la historia. Algo muy similar a lo que propone hoy Bob Jessop (2018) que coincide con el primero en la medida en que comprenden la complejidad de una sociedad que es dinámica, que está viva y se transforma así misma mediante los conflictos sociales. No existen dos Estados iguales, quizás sociedades con pasados en común, como es el caso de América Latina, pero la constitución de la estatalidad y la capacidad de agencia que el Estado ha logrado coordinar para gestionar los intereses de clase es variada, en muchos casos similar pero nunca igual.

Dos simples frases parecieran ayudar a resumir gran parte de la historia del Estado moderno en su diversidad. Michael Mann comienza la descripción del Estado moderno en el segundo tomo de 'fuentes del poder social' diciendo: "El nacimiento del Estado moderno es idéntico al de la mafia, gente que te ofrece protección de ellos mismos" (1991, p. 626). Y es que el Leviatán, aquella figura mítica que era inevitable debido al 'estado de naturaleza' asumía la seguridad para dar tranquilidad, para dejar de un lado la guerra perpetua y dar margen a las sociedades de desarrollarse sin miedo a tener que usar la violencia. El Leviatán hoy cambió, ya no ofrece seguridad porque no la puede garantizar, está excedido en la medida en que las contradicciones de clase y el capital llegaron a un punto donde el Estado no le queda más que gestionar los conflictos que se dan en su seno cediéndole el poder a quienes un día lo habían cedido los reales representantes de la clase dominante. 
¿Cómo lo logra? Tal como lo pronosticó Carl Schmitt cuando mencionaba que el "Protego ergo te obligo es el Cogito ergo sum del Estado (...)" (2009, p. 82). El Estado logra gestionar los conflictos que se generan en su interior gracias a la imposibilidad de cuestionar el contrato social o como lo llamó Lefebvre: el contrato ciudadano. Contrato que no es lo mismo que la Constitución Política, es algo que va más allá, es lo que Kelsen presumía y categorizaba como norma hipotética fundamental, Herbert Hart como regla de reconocimiento o Dworkin como modelo axiológico. Siempre abstracto, universal e incuestionable. Tal contrato ciudadano es lo que impulsó las equivalencias entre las mercancías, premió la producción de ciudadanos y la proliferación de sujetos de derecho con una única y excluyente capacidad real: adquirir propiedad. Relaciones jurídicas que permearon las relaciones sociales y propagaron equivalencias aparentes entre los seres humanos -tal como con las relaciones de intercambio- pero que, excluyeron e igualaron a su conveniencia a hombres y mujeres, indígenas y negros, campesinos y ciudadanos en unidades idénticas y equivalentes por el misma apetito de generar valores de trabajo abstracto que fueran útiles para desconocer las particularidades y promover la igualdad jurídica mientras encubre la desigualdad material.

Mientras el trabajo que crea valor de cambio es trabajo abstractamente general e igual, el trabajo que crea valor de uso es trabajo concreto y particular, el cual, de acuerdo a la forma y el material, se divide en modos de trabajo infinitamente diversos (MARX, 1981, p. 19)

En la sociedad neoliberal el Estado sirve como instrumento en el que todos establecen relaciones de aparente igualdad pues la mercancía que en todo ser humano subyace, la fuerza de trabajos y convirtió en la abstracción que permitió las equivalencias de gentes múltiples y diversas, siendo ese el abrebocas de la cruel y frontal lucha a todo lo que no se encuadrara en la racionalidad moderna. No en vano, Hegel consideraba al Estado moderno como la 'máxima eticidad' ${ }^{1}$, pues en él recaía la misma pluralidad de la sociedad europea que sustentaba y tutelaba la familia, la sociedad civil y el Estado. Máxima eticidad en la que mujeres, negros, indios y la naturaleza, no participaban pues ni eran personas ni contaban con propiedad privada. Tan claro era ello para Hegel que, en las Lecciones sobre la filosofía de la historia

\footnotetext{
${ }^{1}$ Incansablemente enfatiza Hegel que la primera parte de su obra (La Filosofía del Derecho), consagrada al
} 
universal, frente al obstáculo de explicar el porqué los negros eran esclavos y no tenían propiedad escribió: "Lo que entendemos como África es lo segregado y carente de historia, o sea lo que se halla envuelto todavía en formas sumamente primitivas, que hemos analizado como un peldaño previo antes de incursionar en la historia universal. (Hegel, 1980, p. 179).

El largo proceso que el Leviatán toleró para su consolidación, adiciona la lo ya planteado bajo los aforismos de Schimtt y Mann, fue el encausar, desde la forma estatal, la cuarta característica del capital con la razón neoliberal: la producción de mercancías mediante otras mercancías. Desfigurando la forma de la creación de la mercancía que había sido objeto de discusión por más de dos siglos, la forma valor-trabajo.

La reducción al mínimo del trabajo necesario amplía el tiempo del no trabajo y abre la posibilidad de una subjetividad distinta que no produzca sólo riquezas, valores de cambio, sino que pueda producir valores de uso y disfrutar de ellos. (MONCAYO, 2018, p. 83)

Algo que puede plantearse desde lo urbano desde una perspectiva en la cual, la reorganización de los flujos de trabajo, especialmente en la ciudad, ya no depende de la fabrica pues la virtualidad y la informalidad se convirtieron en el escenario adecuado para desencajar las relaciones pre-existentes del mundo del trabajo y así,re-orientar la relación del Estado con sus ciudadanos. El Estado en la razón neoliberal ya no procura en ningún sentido garantizar derechos, bienes o servicios, solo se enfoca en ondular como el garante de la 'satisfacción ciudadana' y el protector de la propiedad privada.

Algo que no deja ser chocante respecto a lo que mencionaba Foucault con el nacimiento de la biopolítica y el control del Estado a manos de los fisiócratas. La síntesis del Estado Keynesiano no se consumó en un Estado relativamente fuerte que ejerciera desde el mercado criterios veridiccionales para limitar el ejercicio del Leviatán, sino que, el Estado pasó a ser un garante de la subjetividad moderna que entiende la felicidad como el criterio bajo el que debería guiarse la estatalidad.

El profesor Emerson Gabardo ayuda a evidenciar ello, al exponer la posibilidad de encontrar criterios objetivos de felicidad, lo que él llama como la felicidad objetiva:

Em suma, os únicos valores passíveis de determinar o conteúdo do princípio da felicida desão justamente aqueles objetiváveis no sistema jurídicoconstitucional e, mesmo assim, não podendo ser beneficiados por uma legitimidade absoluta apriorística e pressuposta. Sua legitimação irá depender da justificação racional intersubjetiva (ainda que não somente dela). Justificação esta que está imersa e condicionada pela história, pela 
mentalidade e pela cultura de um determinado povo, segundo o seu atual estágio civilizatório (...). O Estado tem que possuir critérios objetivos para saber a diferença entre o que a Constituição estabelece como sendo um povo feliz e um povo infeliz (...). O conceito de felicidade objetiva, portanto, não vem sugerir nada além do que o modelo do Estado social já propôs, e o constituinte de 1986-1987 reconheceu expressamente, ainda que, na atualidade, a interpretação do modelo tenha que ser feita em conformidade com o seu tempo. (GABARDO, 2017, p. 130; 131)

La transformación de la subjetividad absorbida por la razón neoliberal es de tal naturaleza que la ciudadanía política que caracterizó el debate del siglo XX pasó a ser una ciudadanía económica, que estima a los espacios que habita en razón a la felicidad que estos le puedan producir mediante los valores de uso. La hipótesis de Emerson Gabardo lo único que permite poner en evidencia es quela teoría del derecho y las instituciones jurídicas neoliberales ya no funcionan únicamente como instrumento para que las clases dominantes gestionen sus intereses, sino, además, para despolitizar cualquier contradicción que surja al interior del Estado. La tecnocracia y la teoría jurídica objetivaron la felicidad y la conmutaron como insumo para fundamentar una política pública que, al hacer la fila del supermercado, permita los ciudadanos solo se preocupen por gestionar el síndrome de Estocolmo que les hace abrazar con firmeza al Leviatán.

¡Por el derecho a ser infeliz!

Las ciudades Latinoamericanas son múltiples, diversas y plurales. Son el reflejo del tejido social que las hiló en medio de la cruenta batalla por sobrevivir al convulsionado s. XX y ahora, por existir en el s. XXI. La historiade las ciudades en Colombia pareciera haberse impulsado entre las ciudades imaginadas de Gabriel García Márquez y las foráneas que asignaba a quienes la habitaban la forma correcta de interactuar con el mundo occidental, la circulación de mercancías que en ella debía existir. Una intentando enterrarla crueldad de la otra, los ideales quede ella brotaron y los feroces procesos que transformaron el paisaje, a los 'perdidos' en las montañas y la naturaleza que ahí existía. Las ciudades imaginadas eran algo más que relatos de José María Arguedas, Juan Rulfo o Gabriel García Márquez, las ciudades imaginadas son el viejo y añorado recuerdo de la naturaleza como elemento de referencia que tenían las gentes antes de ser ciudadanos haciendo filas en el supermercado. 
José Arcadio Buendía, que era el hombre más emprendedor que se vería jamás en la aldea, había dispuesto de tal modo la posición de las casas, que desde todas podía llegarse al río y abastecerse de agua, con igual esfuerzo, y trazó las calles con tan buen sentido que ninguna casa recibía más sol que otra a la hora del calor. En pocos años, Macondo fue una aldea más ordenada y laboriosa que cualquiera de las conocidas hasta entonces por sus 300 habitantes. Era en verdad una aldea feliz, donde nadie era mayor de treinta años y donde nadie había muerto. (...). (GARCÍA, 2007, p. 8)

Fernándo Guillén (2016), reconocido sociológico describió gran parte del proceso de la consolidación de las élites en Colombia como un pacto asociativo de la oligarquía que logró acallar las masas que se habían levantado con la muerte de Jorge Eliecer Gaitán y en la que Bogotá quedó destruida. Acuerdo que permitió que el monocultivo de tabaco y banano se consolidara y con ello que:

Los cambios demográficos, tecnológicos, en las formas de la propiedad, son absorbidos por un modelo de estructura social que encuadra a la población en su totalidad sin otro conflicto expreso y reconocido que el que surge de las divergencias y violencias entre los dos partidos políticos tradicionales. (GUILLÉN, 2016, p. 416)

El resultado de los procesos políticos de mitad del s. XX que se desdoblaron entre la violencia bipartidista (BORDA, 2018) y los pactos asociativos de la oligarquía terminaron por favorecer al capital, disolviendo cualquier contradicción entre la ciudad y el campo. Los partidos políticos que habían logrado sostener su poder en medio del Bogotazo percibieron que las lealtades, propias de la hacienda y el compadrazgo que se había heredado de las ficciones jurídicas de la colonia, especialmente la encomienda, eran útiles para promover paternalismos políticos en la población y una clase media que tenía dos características muy útiles para la consolidación de lo urbano: la lealtad inquebrantable a la élites y una movilidad social que estaba restringida a respetar el clientelismo y el compadrazgo como formas de ascenso social.

Esta lealtad policlasista, arraigada en la necesidad de seguridad y en la ansiedad de obtener prestigio como instrumento de la movilidad ascendente, ocultó y disolvió la conciencia de las desigualdades, haciendo olvidar públicamente -por ejemplo- la existencia de continuas y sutiles discriminaciones raciales y religiosas, que en otras culturas y en otras estructuras asociativas son cuestiones públicas patentes, reconocidos focos de conflicto social explícito. Aunque, como tendencia implícita, esta inclinación oligárquica hace también del patrimonio cultural de las clases más bajas, el tipo de organización que representa al sindicato, garantizando la seguridad en el empleo y ofreciendo otra forma de participación en el poder y en la seguridad social, fue eliminando lentamente la eficacia de ese esquema 'policlasista', mientras que las clases medias eran arrastradas por ella con eficacia sorprendente." (GUILLÉN, 2016, p. 437) 
La borrosa línea de las gentes y los ciudadanos que comienza a disputarse el espacio urbano en Colombia pareciera hacerse visible en el ya viejo, pero siempre actual Karl Polanyi (2003). La tensión política que se interrumpió con la caída del muro de Berlín junto con la victoria cultural y económica del capital hizo que la ciudad y la producción de los espacios que en ella existen, se tornaran mercados autorregulados que excluyen dependiendo de las mercancías ficticias que se encuentren en el espacio: naturaleza (tierra), trabajo y dinero. Las élites económicas y políticas del país soñaron un orden y ese orden se llevó a lo urbano. Las gentes se convierten en ciudadanos libres para vender su fuerza de trabajo, pero nunca como iguales, pues el acceso a la naturaleza(tierra), al trabajo y el dinero estaba limitado por la ambivalencia de las relaciones sociales que se crearon la colonia y se trasplantaron a las ciudades. Bogotá no es simplemente la ciudad de la élite colombiana, es el dispositivo de control de los imaginarios.

La ciudad como teatro de representación del poder representa al Estado y consecuentemente a quienes usufructúan su control. Y es que nada de lo que existe en el espacio urbano es casual: los barrios, las calles, el sentido de quienes viven entre la cordillera y quienes fueron expulsados a las periferias. Inclusive, la disputa por la noción de lo público que se consolidó en el imaginario colectivo con el simbolismo del parque, de los andenes o el transporte, mientras se privatizaba el espacio en el cual se realiza la toma de decisiones de lo urbano: la democracia. ¿Cómo se logró eso? Con los mismos instrumentos que el capital constituyó para su reproducción: las reglas jurídicas y los principios constitucionales.

En Colombia, desde la ley 388 de 1997 se comenzaron a gestar los principales instrumentos para el ordenamiento territorial de las ciudades. Los Planes de Ordenamiento Territorial (POT) más que una simple regla instrumental urbanística es el conjunto de objetivos, políticas, estrategias y metas que orientan el desarrollo de las ciudades y la utilización de los usos del suelo que tiene vigencia como mínimo de doce años. A esto debe sumársele un fenómeno atípico en toda América Latina: los estratos sociales.

Las ciudades colombianas están divididas en estratos sociales, lo que no deja ser una confección para mantener la división de clases en un espacio concreto mientras, 
a la par, se consolida la segregación no como un efecto contingente, sino, como instrumento que delimita las fronteras sociales, espaciales y materiales de quienes habitan la ciudad. El método usado está concebido en la ley 142 de 1994, que 'casualmente' es la misma normativa que establece el régimen de los servicios públicos domiciliarios y sobre la cual se desgarra el monopolio de la prestación que encabezaba el Estado. Su creador, el entonces director de del Departamento Nacional de Planeación, Hugo Palacios Mejía cuenta que:

(...) de acuerdo con la Constitución, pueden considerarse como "servicios públicos domiciliarios" todas las actividades ordenadas a la generación o captación, transformación, transmisión o transporte, distribución, comercialización y provisión masiva de aquellos bienes de consumo y servicios de naturaleza homogénea, producibles en masa por empresas y mediante un régimen de tarifas, que, en cada etapa de desarrollo económico y social, todos los residentes en el país necesitan en forma continua en su lugar de habitación y trabajo para disfrutar en éste de libertad e intimidad frente a terceros, vivir en forma digna y saludable y adelantar actividades productivas. (PALACIOS; 2007, p. 39)

Es la misma metáfora de las plazas públicas que organizaba a las ciudades coloniales y que eran usadas para afirmar el sentido y la jerarquía social de las oligarquías sociales (ZAMBRANO, 2002, 141) y que, al ser apropiadas lentamente por las clases populares, comenzaron a salir del paisaje. La exhibición de riqueza que se daba antes en lo público pasó a lo privado, algo similar a lo que sucedió con la razón neoliberal donde los derechos, en principio públicos, se convirtieron en privilegios que estaban marcados, supuestamente, por la capacidad de un mercado para autoregularse.

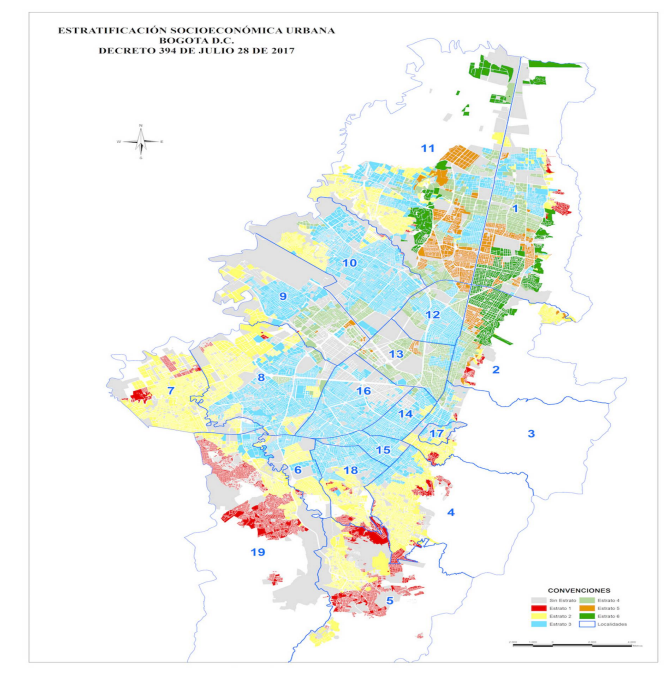

Fuente: Decreto 394 del 2017

Rev. Direito e Práx., Rio de Janeiro, Vol. 11, N. 01, 2020, p. 440-469.

Anibal Alejandro Rojas Hernández, Paula Harumi Kanno e Carlos Frederico Marés de Souza Filho

DOI: 10.1590/2179-8966/2020/48216| ISSN: $2179-8966$ 
El mapa de la ciudad de Bogotá muestra tanto la sectorización de la riqueza, como la de la pobreza y con ello, el acceso que tiene cada grupo social a derechos fundamentales mínimos. Recuerda tal situación a Lefebvre cuando menciona que "Para la clase obrera, víctima de la segregación, expulsada de la ciudad tradicional, privada de la vida urbana actual o posible, se plantea en un problema práctico y por tanto político" (1978, p. 122). Problema político que en Bogotá se ha acallado bajo el discurso de lo técnico, de representantes de la clase política que intentan despolitizar la ciudad e invisibilizar la segregación generando ciudadanos 'felices'.

El caso de Enrique Peñalosa, actual alcalde de la ciudad de Bogotá es de gran ayuda para presentar el cómo, con la producción del espacio -valor de cambio- de la ciudad de Bogotá junto con la estratificación de fines del s. XX, se logró que los ciudadanos que habiten los espacios siendo felices. Es como llevar a la política pública la distopía de Aldous Huxleyen donde ser el 'salvaje' es el que reclama el derecho a ser infeliz (2014, p. 176).

Dos fueron las apuestas del burgomaestre en el cuatrienio 2016-2019: el plan de desarrollo Bogotá Mejor para Todos y la propuesta de POT a serla hoja de ruta vinculante para la ciudad de Bogotá para los doce años posteriores. El plan de desarrollo, adoptado mediante el Acuerdo 645 de 2016 tiene como propósito explicito, en su art. 2: “(...) alcanzar la felicidad de todos en su condición de individuos, miembros de la familia y de la sociedad". Elemento que no deja de ser transversal a la política pública del alcalde y que se complementa bajo el proyecto de Acuerdo para el POT que en su art. 1 dispone: "El ordenamiento del territorio bogotano busca mejorar la calidad de vida y alcanzar mayores niveles de felicidad y de bienestar integral individual". Cosa que invita a pensar ¿en dónde reside tal criterio de felicidad?

No deja de ser interesante observar que la economía como una rama específica del conocimiento comenzó a estudiar el tema como un conjunto de vivencias afectivas y sensoriales que se adscriben a la economía conductual, la misma que entiende al ser humano como un homo economicus. Otra paradoja más del s. XXI, pues en realidad continúa asemejando a la utilidad y la felicidad como fines en sí mismos, es decir, sigue determinando la satisfacción de los seres humanos en su consumo. Un punto que amerita especial atención, pues ahí es donde se delimita la democratización de los espacios urbanos a los ideales que perpetúan una forma de consumo que suele 
estar en absoluta contraposición a la resiliencia de la naturaleza y el factor socioambiental de los territorios.

Uno de los ejemplos más sugestivos para ilustrar y que son el resultado de las ya citadas propuestas de Enrique Peñalosa, son los Centros de Felicidad (CEFE), espacios que los estudios previos para la licitación definen como: "mega-centros deportivos, recreativos y culturales ubicados en los parques más importantes de la ciudad (...). Centros que coinciden con los espacios en los que coexisten estratos 0,1 y 2 dentro de la ciudad de Bogotá y que, pareciera reñir con la naturaleza que aún subsiste -en forma de parques urbanos- al ser precisamente en esos espacios donde se realizarán los Centros de Felicidad. Todo eso no podría ser más que una 'afortunada' casualidad con el Global Happiness Policy Report del 2018 que entre sus recomendaciones está:

A city is certainly a de facto arena for public life. In the Mayor's Guide to Public Life, public life is seen as what "happens in public spaces, on streets, and in between buildings... thrives when all people can enjoy being in public together." The guide further describes a vibrant public life such that it "promotes health, makes our cities safer... civic engagement... economic opportunity and mobility, builds social capital, and connects people to their local communities." (...). Many cities conduct citywide events aimed at boosting physical exercise and healthy habits. For example, as a way to boost both health and happiness in Dubai, the city leadership challenged the residents to a fitness drive. (GLOBAL HAPPINES COUNCIL, 2018, p. 170)

La distopía de las sociedades felices que ha encontrado cierto asidero en la ciudad de Bogotá no deja de indicar que la urgencia de estudiar la producción del espacio urbano actual con criterios no homólogos es vital. Los CEFE en la ciudad de Bogotá parecieran haber inspirado a Lefebvre cuando dice que: “(...) la naturaleza como espacio, con el espacio, es a la vez despedazado, fragmentado, vendido por partes y ocupado globalmente. Ella es destruida como tal y reorganizada según las exigencias de la sociedad neocapitalista" (1972, p. 45). Espacio social en el que, al producirse, no solamente muta el paisaje, también se transforman lo que Bolívar Echevarría (1998) llamó la socialidad. La sociedad foránea está llena de valores de cambio, mientras Macondo, la sociedad imaginada, está impregnada y atiborrada de valores de uso.

Los estratos sociales tienen múltiples y poco estudiados efectos desde la teoría marxiana en la constitución del espacio y en las prácticas de clase que se desdoblan en él. La ciudad como obra (valor de uso) o como producto (valor de cambio) es lo que pareciera alterar profundamente el espacio urbano de la ciudad de Bogotá. Quienes 
sobreviven en los estratos 0 (sin estrato), 1 o 2 , son personas que conviven en sectores de la ciudad que, al traslapar los mapas, evidencia que la cartografía de la ciudad en esos mismos estratos está marcada por la violencia, el narcotráfico, el no acceso a la tierra, los servicios públicos, al trabajo y una inexistente movilidad social. La otra Bogotá, la que nunca buscó un consenso para estructurarse, vio la posibilidad de generar una ciudad foránea que se produjo en la periferia privilegiando los valores de cambio a los valores de uso.

¿Por qué? ¿Qué importancia tiene que la ciudad de Bogotá fuera estratificada en la periferia con valores de cambio? Los valores de uso, que según Bolívar Echevarría "tratan de una forma 'natural' de producir y consumir las transformaciones de la naturaleza, y sobretodo, de ratificar y modificar la figura concreta de la socialidad" (1998, p. 167). Macondo, la ciudad imaginada está llena de valores de uso que transforman la sociabilidad de las personas que cohabitan el espacio. La ciudad como obra, como valor de uso, es un concepto liberador que agrieta al valor de cambio y genera responsabilidad con el entorno en el que se vive, pues es ahí donde se produce la reproducción vital de su cultura, su vida y su entorno. Si se quiere, es la misma relación que resiste entre las gentes que conviven armónicamente con la naturaleza, ese es el origen de su libertad y al mismo tiempo, de la zozobra del capital por darle a la naturaleza un valor de cambio.

Nuevos relatos que disputen el tiempo y la naturaleza: el derecho socioambiental a la ciudad

La Constitución francesa de 1791, la resultante de la revolución burguesa, la de las revueltas de harina, la de mujeres que se levantaron contra la desigualdad del sistema feudal, se cimentó con base en la moderna idea del sufragio universal. La noción de lo 'universal' está absolutamente delimitada no solo por la Declaración de los Derechos del Hombre, pues en el siglo de las luces, los ciudadanos-propietarios ${ }^{2}$ aseguraban de cierta forma que el acceso a la ciudadanía estuviera demarcado por ciudadanos con tierra para

\footnotetext{
2“Aún cuando forman efectivamente una clase, los propietarios no sólo se distinguen del pueblo: se oponen a la entrada al mundo de los privilegiados y de los titulares del cargo" (ROSANVALLON, 1999, p. 48)
} 
transferir, trabajar y de la cual, a su vez, el Estado lograra hacer tributar. La tierra no era la de la vieja noción de Locke que promulgaba el trabajo concreto en ella, era la tierra de los fisiócratas, la que menciona Anne Robert Jacques Turgot a Richard Price en carta sobre las Constituciones americanas de 1778:

No veo que se haya prestado atención a la gran distinción (la única fundada en la naturaleza) entre dos clases de hombres: la de los propietarios de la tierra y la de los no propietarios; a sus intereses y, por lo tanto, sus diferentes derechos respecto a ala legislación, a la administración de justicia y de la policía, a la contribución del gasto público y a su empleo. (DE LA NUEZ, 2015, p. 250)

Una propiedad que origine privilegios individuales al punto de extenderse a lo público supuso un desequilibrio no solamente para quienes se encontraban en la ciudad, sino, para todos los seres humanos que veían entrar al Estado moderno con una violencia que no habitaba necesariamente en la pólvora de las armas al detonar. La perspectiva que se asentó a partir de la primavera de 1789 premió la construcción de una identidad colectiva en el chauvinismo nacionalista que se enfoca en sosegar a lo diverso.

La propiedad entonces no significa más que un espacio que genera riqueza en la medida en que se aproveche, poco importando la vida que ya estaba ahí. La propiedad moderna es la propiedad que aprovechó a la naturaleza para utilizarla creyendo que, al cercarla, limpiarla y monocultivarla, ella estaría domada, quieta o quizás muerta. Es la naturaleza que el capital olvidó que está tan viva que incluso los dioses de los seres humanos están sometidos a ella pues en últimas, sin gentes no hay dioses, tal como ha sucedido en los largos ciclos de la naturaleza que ha creado vida, se ha transformado con ella y siempre que lo ha necesitado, ha continuado en otro de sus ciclos, con deidades o sin deidades.

Son dos las posiciones que se disputan en la modernidad lo que implica la naturaleza y la relación de los seres humanos con ella. La primera, heredada de las reflexiones de Epicuro de Samos mientras filosofaba en el jardín con quienes el mundo griego jamás consideró dignos de tener ciudadanía y siempre expulsó: mujeres y esclavos. Naturaleza que vibra y en algún tiempo se entendió como Physis ${ }^{3}$. Hoy, con un significado similar a la queso porta la vida que hace que pueblos indígenas, negros y

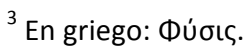


campesinos la distingan como una madre y como su sustento, debiéndole un cuidado y una armonía. Es una naturaleza en que la propiedad poco importa y en la que, quienes la habitan a su vez la escuchan, la comprenden y le dan remedios para curarla, dejándola descansar.

La segunda concepción es más moderna y heredada del latín natura. Es la naturaleza que en el mundo de los hombres blancos está destinada a ser sometida y apropiada; es la naturaleza de la propiedad privada moderna en donde su función es ser una materia prima, un commoditie que para el capital genera riqueza individual y para la vieja y desgastada ortodoxia marxiana, es fuente de riqueza inerte que el Estado debe explotar y distribuir.

Entre physis y natura se encuentran las gentes que resisten ver el espacio como propiedad al entenderlo como vida. Una vida que les es ajena y respetan; una vida que los alimenta y que en los días de calor les brinda un lugar para estar a la sombra y agua para saciar su sed. Una vida que es común a todas las gentes, que no distingue entre propietarios y expulsos, entre esclavistas y esclavos, poderosos o dominados, cercas, contratos de propiedad o leyes. Es la naturaleza, o mejor, la physis que brota para darle sentido y sustento a las gentes, a las ciudades y a los ciudadanos. Es una naturaleza con sentido, que corta el lazo que el Estado moderno vinculó al ciudadano con la propiedad.

Quizás, es por eso por lo quela relación de la ciudadanía está fundada en un contrato desigual en donde los ciudadanos-propietarios se oponen a lo popular: el pueblo. Ese pueblo que sobrevive en el espacio abstracto en un 'estado de naturaleza' (ROJAS, 2019) son los mismos a los que la modernidad expulsó (DE SOUZA, 2015) y que encajan en la misma disputa sobre la cual los Estados Latinoamericanos se transformaron. Son los que enaltecieron los derechos colectivos y los resignificaron desde su relación con la naturaleza, con el espacio concreto en el que habitan y que hoy se convirtieron en la punta de lanza para hacer una afrenta a las ciudades de foráneos desde sus propias ciudades imaginadas. Mientras el ciudadano-propietario que hace la fila de supermercado procura ser feliz sobrellevando su consumo, los expulsos, los que tienen una noción socioambiental del espacio, mujeres, indios, negros e inclusive, la misma naturaleza, cuestionan lo individual y se apropian de lo común.

Estes direitos coletivos que são sociais porque correspondem a sociedades, comunidades, grupos ou a todos de uma só vez, e são ambientais, porque 
correspondem tanto ao ambiente natural (natureza) como o artificial criado pela cultura e conhecimentos humanos (patrimônio cultural, conhecimento tradicional associado à biodiversidade), podem ser chamados de direitos socioambientais. Correspondem a direitos que, diferentes dos individuais e estatais, não se integram a um patrimônio seja particular seja estatal. São patrimônios que pertencem a muitos ou a todos e que convivem no espaço intermediário, entre o Estado e o cidadão e disputam, interferem e modificam os mais consolidados direitos individuais e os mais rígidos direitos públicos estatais. (DE SOUZA, 2017, p. 212; 213)

El espacio abstracto en el que Lefebvre entiende que se desdobla la más cruel violencia es así pues es el lugar ideal en el cual la producción del capital le dio a la ciudad una función de valores de cambio, “(...) la reproducción de las relaciones sociales de producción, asegurada por el espacio y en el espacio, implica, a pesar de todo, un uso perpetuo de la violencia (2013, p. 224). La contradicción es la siguiente: las luchas de las gentes que retornaron a la modernidad después de cientos de batallas han logrado permear los sistemas jurídicos y con ello, hicieron cierta una de las dos conclusiones posibles del capital según Marx, la falla metabólica de la naturaleza.

El latifundio reduce la población agraria a un mínimo siempre decreciente y la sitúa frente a una creciente población industrial hacinada en grandes ciudades. De este modo da origen a unas condiciones que provocan una fractura irreparable en el proceso interdependiente del metabolismo social, metabolismo que prescriben las leyes naturales de la vida misma. El resultado de esto es un desperdicio de la vitalidad del suelo, que el comercio lleva mucho más allá de los límites de un solo país. [...] La industria a gran escala y la agricultura a gran escala explotada tienen el mismo efecto. Si originalmente pueden distinguirse por el hecho de que la primera deposita desechos y arruina la fuerza de trabajo, y por tanto la fuerza natural del hombre, mientras que la segunda hace lo mismo con la fuerza natural del suelo, en el posterior curso del desarrollo se combinan, porque el sistema industrial aplicado a la agricultura también debilita a los trabajadores del campo, mientras que la industria y el comercio, por su parte, proporcionan a la agricultura los medios para agotar el suelo. (Marx, 2009, pp. 949-950)

Un espacio abstracto que se resignifique desde un derecho a la ciudad que premie la noción de lo socioambiental, no solo disputa la producción de ciudades intentándolas reconstituir como obras, como valores de uso que se relacionan específicamente con las gentes que allí habitan, disputa bravamente la superestructura de la modernidad pues altera la matriz en que se articula el modo de producción imperante del capital: la propiedad privada. Cuestionándola en una doble vía: la sociedad como una mercancía ficticia que se hace útil para la reproducción de mercancías mediante otras mercancías y, quizás lo más notable de tal movimiento, 
haciendo evidente que evitar la fractura de la naturaleza es una forma de cuestionar el contrato mismo de la ciudadanía.

Los defectos inevitables que brotan del capital están en la estructura misma del Estado pues en ninguna circunstancia el sistema jurídico puede ser superior al modo de producción y a la estructura económica y como es natural, ello termina reflejando en que el mismo derecho a tener un hogar se trasfiguró al privilegiar los valores de cambio y no de uso. La ciudad se produjo como una mercancía en la que el derecho a vivir en ella se subordinó a los valores de cambio que privilegian la acumulación del espacio, donde el uso se somete a la renta de los ciudadanos o a las acciones colectivas de las gentes que, desterradas desde un principio de la ciudad, hoy confrontan la sagrada propiedad privada y ejercen su derecho a vivir en los espacios en los que el valor de cambio se impuso.

Nuevos relatos que disputen el tiempo presuponen, necesariamente, reconocer que las acciones colectivas de quienes siempre han estado fuera de la modernidad son las que cambian la estructura económica con su solidaridad y al sistema jurídico con su resistencia. Son relatos que batallan en el tiempo pues tal como sucedió con la Ocupação Quilombo das Guerreiras en Rio de Janeiro, lo que se riñe no es el concreto que reposa en la naturaleza, es el valor de uso que genera para todos los que se quedaron afuera.

Un derecho socioambiental a la ciudad es uno de los tantos derechos colectivos que recaen sobre la diferencia, las prácticas culturales y la integración social. Derechos comunes que se atiborran de gentes que ejercen la felicidad individual desde la libre autodeterminación social. Un derecho a la ciudad es el que forcejea en lo rural y en lo urbano por territorios interétnicos que no estén desarmonizados socioambientalmente. Es un derecho que entiende a la naturaleza globalmente, con sus facetas, contradicciones y particulares. Es un derecho a la ciudad de gentes que hacen de la naturaleza el elemento central de su socialidad, de su consumo, sus prácticas y su patrimonio común.

\section{Referencias bibliográficas}

ALDOUS, H. Un mundo feliz. México D.F.: Ediciones del sindicato nacional de trabajadores del infonavit, 2004. 
ARENDT, H. Sobre la violencia. Madrid: Alianza Editorial, 2006.

ARIAS SÁNCHEZ, M. Bogotá D.C. durante 1998-2018. Análisis de caso del sistema de planificación urbana en Colombia. Revista Ciudades, Estados y Política, v. 5, n. 1, p. 3357, 2018.

BORDA, F. O.; GUZMÁN CAMPOS, G.; UMAÑA LUNA, E. La violencia en Colombia, Tomo I. Segunda ed. Bogotá D.C.: Taurus, 2018.

CAMARGO SIERRA, A. P.; HURTADO TARAZONA, A. Urbanización informal en Bogotá: agentes y lógicas de producción del espacio urbano. Revista Invi, p. 77-107, 2013. Bogotá D.C.

COLOMBIA. Acuerdo 645 de 2016: Por el cual se adopta El Plan de Desarrollo Económico, Social, Ambiental y de Obras Públicas para Bogotá D.C. 2016 - 2020 "Bogotá Mejor Para Todos". Disponívelem:

<https://www.alcaldiabogota.gov.co/sisjur/normas/Norma1.jsp?i=66271>. Acceso em: 15 dec 2019.

Decreto 394 de 2017: Por medio del cual se adopta la actualización de la estratificación urbana de Bogotá D.C. para los inmuebles residenciales de la ciudad.Disponívelem:

<https://www.alcaldiabogota.gov.co/sisjur/normas/Norma1.jsp?i=7019>.Acceso em: 15 dec 2019.

Estudios Previos Construcción del Centro Felicidad CEFE las Cometas ubicado en la localidad de Suba en la ciudad de Bogotá D.C., 2019. Disponívelem: <https://community.secop.gov.co/Public/Tendering/OpportunityDetail/Index?noticeUID $=$ CO1.NTC.852410\&amp\%3BisFromPublicArea=True\&amp\%3BisModal=False $>$. Acceso em: 15 dec 2019.

Ley 142 de 1994,Disponívelem: <http://www.secretariasenado.gov.co/senado/basedoc/ley_0142_1994.html>. Acceso em: 15 dec 2019.

Ley 388 de 1997,Disponívelem: <http://www.secretariasenado.gov.co/senado/basedoc/ley_0388_1997.html>. Acceso em: 15 dec 2019.

. Proyecto de Acuerdo: "Por el cual se adopta la Revisión General del Plan de Ordenamiento Territorial de Bogotá D.C. Disponívelem: $<$ http://www.sdp.gov.co/sites/default/files/5-PROYECTO-DEACUERDO/PROYECTO\%20DE\%20ACUERDO.pdf>. Acceso em: 15 dec 2019.

DE LA NUEZ, P. A.R.J. Turgot: Carta al Doctor Richard Price sobre las Constituciones americanas (22 de marzo de 1778). Eunomía. Revista en Cultura de la legalidad, v. 1, n. 8, p. 242-253, 2015. Madrid. 
ECHEVARRÍA, B. Valor de uso y utopía. Primera ed. México D.F.: Siglo Veintiuno Editores, 1998.

ELSTER, J. MakingSense of Marx. Cambridge: Cambridge UniversityPress., 1985.

FEDERICI, S. Calibán y la bruja: Mujeres, cuerpo y acumulación primitiva. $1^{\circ}$ ed. Madrid: Traficantes de Sueños, 2010.

FRASER, N. Por trás do laboratório secreto de Marx. Revista Direito\&Práxis, v. 6, n. 10, p. 704-728, 2015. Rio de Janeiro.

GABARDO, E. A felicidade como fundamento teórico do desenvolvimento em um Estado Social. REVISTA DIGITAL DE DIREITO ADMINISTRATIVO, v. 5, n. 1, p. 99-141, 2018. GUILLÉN MARTÍNEZ, F. El poder político en Colombia. Segunda ed. Bogotá D.C.: Editorial Planeta, 2016.

HAN, B.-C. Topología de la violencia. Primera ed. Barcelona: Herder, 2016.

HEGEL, G. W. F. Lecciones sobre la filosofía de la Historia Universal. Madrid: Alianza Editorial, 1980.

JESSOP, B. El Estado. Madrid: Catarata, 2018.

JHON BELLAMY FOSTER. La ecología de Marx. Primera ed. Madrid: El Viejo Topo, 2000.

KELSEN, $H$. ¿Qué es la justicia?. México D.F. Disponívelem: <https://www.ijf.cjf.gob.mx/cursosesp/2018/Octubre/Seminario_Maria_Cristina_Salmo rán_Teorias_Contemporaneas/MATERIAL\%20DE\%20LECTURA/0.\%20PRELIMINARES/1.\% 20AUTORES\%20CLÁSICOS/2.\%20Kelsen.pdf>. Acceso em: 15 dec 2019.

LEFEBVRE, H. (2013). La producción del espacio. Madrid: Capitán Swing.

H. El derecho a la ciudad. Barcelona: Ediciones Península, 1978.

H. Space and mode of production. IN: BRENNER, N. State, Space: world selectedessays. Minneapolis: University of Minnesota Press, 1991.

MANN, M. Las fuentes del poder social II: el desarrollo de las clases y los Estados nacionales (1760-1914). Primera ed. Madrid: Alianza Editorial, 1997.

MARIÁTEGUI, J. C. 7 ensayos de interpretación de la realidad jurídica peruana. Lima: Biblioteca Ayacucho, 2007.

GARCÍA MÁRQUEZ, G. Cien años de soledad. Primera ed. Madrid: RAE, 2007.

MARX, K. Contribución a la crítica de la economía política. Novena ed. México D.F.: Siglo Veintiuno Editores, 2008. 
K. El 18 Brumario de Luis Bonaparte. Primera ed. Madrid: Fundación Federico Engels, 2003.

K. El Capital el proceso de producción del capital, vol III. Madrid: Siglo XXI editores, 2009.

K. Escritos sobre materialismo histórico. Primera ed. Madrid: Alianza Editorial, 2012.

MARX, K.; ENGELS, F. Manifiesto del Partido Comunista. México D.F.: Centro de Estudios Socialistas Carlos Marx, 2011.

MIRANDA, J. P. Hegel tenía razón. El mito de la ciencia empírica. México D.F.: UAMIztapalapa, 1989.

MONCAYO, V. M. El Leviatán derrotado. Segunda ed ed. Bogotá D.C.: Ediciones Aurora, 2018.

PALACIOS MEJÍA, H. La Constitución y la especialización de las funciones de protección a la competencia en materia de servicios públicos domiciliarios. REVISTA DE DERECHO Y ECONOMíA, v. 21, n. 1, p. 39-56, 2007.

POLANYI, K. La Gran Tansformación: los orígenes políticos y económicos de nuestro tiempo. México D.F.: Fondo de Cultura Económica, 2003.

POULANTZAS, N. Las clases sociales en el capitalismo actual. Primera ed. Buenos Aires: Siglo Veintiuno Editores, 1976.

, N. Poder político y clases sociales en el Estado capitalista. $29^{\circ}$ ed. Buenos Aires: Siglo Veintiuno Editores, 2001.

ROJAS HERNÁNDEZ, A. A. La forma fantasmagórica de la modernidad: cuerpos e identidades expulsas. Cuadernos de Filosofía Latinoamericana, v. 40, n. 120, p. 69-86, 2019.

ROSANVALLON, P. La consagración del ciudadano: historia del sufragio universal en Francia. Primera ed. México D.F.: Instituto Mora, 1999.

SCHMITT, C. El concepto de lo político. Quinta ed. Madrid: Alianza Editorial, 2009.

SOUZA FILHO, C. F. M. DE. A essência socioambiental do Constitucionalismo LatinoAmericano. Revista Faculdade de Direito da UFG, v. 41, p. 197-215, 2017.

C.F.M. De como a natureza foi expulsa da modernidade. Revista Crítica do Direito, v. 66, p. 88-105, 2015.

SPINOZA, B. Tratado Breve. Madrid: Alianza Editorial, 1990. 
STUČKA, P. I. La función revolucionaria del derecho. Segunda ed ed. Barcelona: Ediciones Península, 1974.

THE GLOBAL HAPPINESS COUNCIL. Global Happiness Policy Report 2018. New York: Sustainable Development Solutions Network, 2018. Disponível em: <https://www.worldgovernmentsummit.org/api/publications/document?id=304a8bc4e97c-6578-b2f8-ff0000a7ddb6>. Acceso em: 15 dec 2019.

ZAMBRANO PANTOJA, F. De la Atenas suramericana a la Bogotá moderna. La construcción de la cultura ciudadana en Bogotá. Revista de Estudios Sociales, v. 11, p. 9-16, 2002. Bogotá D.C.

ZIZEK, S. Primero como tragedia, después como farsa. Madrid: Akal, 2009.

Sobre os autores

\section{Anibal Alejandro Rojas Hernández}

Profesor Sociología Jurídica Universidad Nacional de Colombia. Abogado, Magister en Derecho Socioambiental por la PUC-PR, candidato a PhD en Ciencias Sociales y Humanas por la UNAL-Colombia y en Derecho Socioambiental por la PUC-PR. Investigador del Centro de Pesquisa e Extensão em Direito Socioambiental (CEPEDIS). Coordinador de la línea de investigación justicias otras del grupo de investigación Estado y Usos Sociales de la llegalidad (E-ILUSOS). E-mail: anilejo@hotmail.com

\section{Paula Harumi Kanno}

Graduanda en Derecho por la PUC-PR. Investigadora del Centro de Pesquisa e Extensão em Direito Socioambiental (CEPEDIS). E- mail: paula_harumi@hotmail.com

\section{Carlos Frederico Marés de Souza Filho}

Profesor titular de Derecho Agrario y Socioambiental en el programa de maestría y doctorado de la Pontifícia Universidade Católica do Paraná (Curitiba/PR/Brasil). Doctor en Derecho por la Universidade Federal do Paraná (1998). E-mail: carlosmares@terra.com.br

Os autores contribuíram igualmente para a redação do artigo. 